\title{
SEGMENTASI KONSUMEN PLAZA ARAYA DAN POSITIONING TERHADAP PESAINGNYA DENGAN MENGGUNAKAN ANALISIS CLUSTER DAN BIPLOT
}

\author{
Amin Tohari \\ ${ }^{1}$ Staff Pengajar di Fakultas Ekonomi Universitas Nusantara PGRI Kediri \\ Jl. KH. Achmad Dahlan No. 76 Kediri \\ e-mail: amin.tohari@unpkediri.ac.id
}

\begin{abstract}
ABSTRAK
Persaingan bisnis yang kompetitif memerlukan pendekatan consumer atau customer driven untuk menentukan produk dan jasa yang akan dihasilkan oleh perusahaan. Agar usaha tersebut dapat bersaing, maka dibutuhkan strategi pemasaran yang tepat, di mana salah satunya adalah segmentasi konsumen. Hasil segmentasi konsumen dapat digunakan sebagai dasar untuk memposisikan dirinya agar berbeda terhadap pesaingnya. Analisis kelompok (cluster analysis) digunakan untuk mengetahui segmentasi konsumen Plaza Araya berdasarkan faktor psikografis. Analisis biplot digunakan untuk mengetahui posisi Plaza Araya terhadap pesaingnya yaitu Mitra I berdasarkan variabel positioning.

Analisis kelompok menghasilkan enam segmen yaitu segmen yang well planned (merencanakan sebelum membeli barang), segmen yang dicirikan oleh konsumen yang membandingkan harga barang yang akan mereka beli, segmen yang tidak mempermasalahkan harga, segmen yang risk taker (suka mencoba hal-hal yang baru), segmen yang memiliki gengsi tinggi dan segmen yang dicirikan oleh konsumen yang lebih mempertimbangkan kualitas karena kualitas bagi mereka adalah nomer satu.

Berdasarkan analisis Biplot diketahui bahwa Plaza Araya lebih unggul dibandingkan dengan Mitra I meliputi penampilan fisik karyawan, Sikap karyawan terhadap konsumen dan kelengkapan barang. Sedangkan Mitra I lebih unggul dibandingkan dengan Plaza Araya dalam hal harga, kualitas dan fasilitas.
\end{abstract}

Kata Kunci: Segmentasi konsumen, Positioning, Analisis kelompok, Analisis Biplot

\begin{abstract}
A competitive bussiness competition needs a consumer approach or customer driven to deciding product and service that will be produced by the enterprise. To join the competition, it needs a right marketing strategy, one of them is a consumer segmentation. This consumer segmentation can be used as a principal to determine its position in order to be different with its competitor. Cluster analysis is applied to know the consumer segmentation of Araya Plaza depend on its psychographic factor. And Biplot analysis is applied to know the positioning of Araya Plaza to its competitor, Mitra I, depend on its positioning variable.

The result of Cluster analysis shows six segments, they are a well planned segment (planning before buying goods), a segment which is characterized by consumers who like to compare the price of goods before buying, a segment which the consumers don't care about the price, a segment of risk taker (prefer trying something new), a segment which has a high prestige, and a segment which is characterized by consumers who consider about the quality because for them quality is priority.

The Biplot analysis shows that Araya Plaza is better than Mitra I in physical performance of its employees, the attitude of its employees to the customer, and also its product completeness. In the other hand, Mitra I is better than Araya Plaza in its price, quality, and facility.
\end{abstract}

Key Word : Consumer Segmentation, Positioning, Cluster Analysis, Biplot Analysis 


\section{PENDAHULUAN}

\section{Latar Belakang}

Persaingan Bisnis yang semakin kompetitif memerlukan pendekatan consumer atau customer driven. Pendekatan ini digunakan untuk menentukan produk baik berupa barang maupun jasa yang akan dihasilkan oleh suatu perusahaan, agar benar-benar merupakan kebutuhan konsumen atau pelanggan. Demikian juga untuk menentukan produk yang akan dijual pada pusat perbelanjaan (shopping center). Shopping center adalah kelompok bisnis eceran (retail) yang direncanakan, dikembangkan, dimiliki dan dikelola sebagai satu unit [1].

Keistimewaan shopping center yang dapat memenuhi semua kebutuhan konsumen dalam satu tempat, menyebabkan keberadaannya semakin dibutuhkan, terutama oleh masyarakat di perkotaan, di mana mereka mempunyai aktifitas atau kesibukan yang tinggi. Hal ini mengakibatkan shopping center tumbuh menjadi bisnis yang menguntungkan.

Agar usaha tersebut dapat bersaing, maka dibutuhkan strategi pemasaran yang tepat. Salah satu bagian dari strategi pemasaran yang perlu diperhatikan adalah tentang pengelompokan (segmentasi) konsumen. Menurut Kotler [2] segmentasi merupakan satu kesatuan dengan targeting dan positioning. Hubungan ini disingkat sebagai STP (segmentation, targeting dan positioning). Segmentasi konsumen, menurut Umar [3] didasarkan pada komponen demografis dan psikografis. Untuk selanjutnya, hasil dari segmentasi konsumen tersebut dapat digunakan sebagai dasar untuk melakukan targeting dan memposisikan dirinya agar berbeda dengan pesaingnya (positioning).

Di kota malang, dengan jumlah penduduk yang selalu bertambah, shopping center merupakan usaha yang menguntungkan. Pada saat ini terdapat sejumlah shopping center, dengan demikian terjadi persaingan usaha yang cukup ketat. Berdasarkan latar belakang tersebut, maka dilakukan penelitian tentang "Segmentasi Konsumen Plaza Araya Dan Positioning Terhadap Pesaingnya Dengan Menggunakan Analisis Cluster dan Biplot".

\section{Rumusan Masalah}

1. Bagaimana deskripsi konsumen Plaza Araya berdasarkan komponen demografis dan psikografis (gaya hidup dan sosial budaya)?

2. Bagaimana segmentasi konsumen Plaza Araya berdasarkan komponen psikografis konsumen?

3. Bagaimana posisi Plaza Araya dibandingkan dengan Mitra I berdasarkan variabel-variabel positioning?

\section{Tujuan}

1. Mendeskripsikan konsumen Plaza Araya berdasarkan komponen demografis dan pskografis (gaya hidup dan sosial budaya).

2. Menerapkan analisis kelompok (cluster analysis) untuk mengetahui segmentasi konsumen Plaza Araya berdasarkan komponen psikografis.

3. Menerapkan analisis biplot untuk mengetahui posisi Plaza Araya terhadap pesaingnya yaitu Mitra I berdasarkan variabel-variabel positioning.

\section{TINJAUAN PUSTAKA}

\section{Segmentasi Konsumen}

Segmentasi konsumen adalah suatu proses untuk membagi-bagi atau mengelompokkan konsumen ke dalam kotak-kotak yang lebih homogen [4]. Menurut Umar [3], ada beberapa komponen utama untuk melakukan segmentasi dalam pemasaran, antara lain komponen demografis dan psikografis, yang secara rinci dapat dijelaskan sebagai berikut:

1. Komponen demografis, seperti usia, jenis kelamin dan pendapatan.

2. Komponen psikografis, seperti kelas sosial, gaya hidup dan kepribadian.

Dalam komponen demografis, konsumen dibagi menjadi kelompok-kelompok berdasarkan variabel-variabel demografis seperti jenis kelamin atau gender, usia, status pernikahan, pendidikan tertinggi yang dicapai, jenis pekerjaan dan pendapatan yang merupakan variabel demografis yang penting [2]. Sedangkan menurut Kasali [4] segmentasi demografis dapat dilakukan dengan membagi pasar ke dalam kelompok-kelompok sebagai berikut :

1. Jenis kelamin (gender)

Identitas gender merupakan elemen penting dalam pemasaran. Memang tidak semua produk dapat dibedakan menurut gender, namun untuk produk-produk yang berhubungan dengan gaya hidup seperti rokok, pakaian, tas, sepatu, kosmetika, majalah, penataan rambut maupun otomotif dapat memakai variabel ini.

2. Usia

Biasanya penduduk dibedakan menurut usia anak-anak, remaja, dewasa dan orang tua. Tetapi definisi ini masih dianggap terlalu luas. Manusia dewasa misalnya, ada dua konsep dewasa, yaitu dewasa secara seksual (dilihat dari perubahan-perubahan seksual yang tampak) dan dewasa secara ekonomi (sudah mampu membiayai hidupnya sendiri).

3. Pendidikan

Pasar dapat dikelompokkan menurut tingkatan pendidikan yang dicapai oleh konsumen. Pendidikan tertinggi yang dicapai konsumen akan menentukan penghasilan dan kelas sosial konsumen. Selain itu pendidikan juga dapat mempengaruhi pilihan barang, merek, jenis hiburan dan sebagainya.

4. Tahap daur ulang keluarga (family life cycle)

Konsumen dapat dikelompokkan menurut tahapan yang dicapai konsumen dalam daur hidup keluarganya. Konsumen pada setiap tahap dalam life cycle tersebut memiliki ciri-ciri konsumsi yang berbeda, dengan sifat yang berbeda-beda pula. Konsumen yang masih single cenderung menghabiskan sebagian waktunya untuk bersenang-senang (fun and enjoyment), sedangkan mereka yang sudah berkeluarga lebih berhati-hati dalam membelanjakan uangnya terutama apabila mereka sudah memiliki anak.

5. Pendapatan

Produk yang dibeli konsumen pada umumnya berkaitan erat dengan penghasilan yang dimiliki oleh rumah tangganya.

Dalam komponen Psikografis, konsumen dibagi menjadi kelompok yang berbeda berdasarkan kelas sosial, gaya hidup 
dan kepribadian. Konsumen dalam kelompok demografis yang sama dapat menunjukkan gambaran psikografis yang sangat berbeda [2].

Menurut Kasali [4], psikografis secara sederhana dapat diartikan sebagai segmentasi berdasarkan gaya hidup. Gaya hidup pada prinsipnya adalah bagaimana konsumen menghabiskan waktu dan uangnya. Sedangkan menurut Kotler [2], gaya hidup konsumen adalah pola hidup konsumen di dunia yang diekspresikan dalam aktifitas, minat dan opininya. Gaya hidup mencerminkan keseluruhan diri konsumen yang berinteraksi dengan lingkungannya.

Gaya hidup mempengaruhi perilaku konsumen dan akan menentukan pilihan-pilihan konsumsi konsumen. Konsumen pada dasarnya membeli bukan hanya karena fungsi barang, akan tetapi barang tersebut memberi arti tertentu bagi dirinya. Barang-barang itu mencerminkan citra diri konsumen dan benda-benda tersebut mengekspresikan gaya hidup mereka [1].

\section{Targeting}

Kasali [4] mangatakan bahwa targeting dalam konteks STP (segmentation, targeting dan positioning) berhubungan erat dengan media yang dapat digunakan untuk menjangkau segmen baru. Ada dua fungsi dalam targeting yaitu menyeleksi pasar sasaran sesuai dengan kriteria-kriteria tertentu (selecting) dan menjangkau pasar (reaching) untuk mengkomunikasikan nilai.

Menurut Umar [3] setelah segmentasi konsumen diketahui, perusahaan perlu mengevaluasi dan memutuskan berapa segmen konsumen yang akan dipilih. Evaluasi dilakukan dengan mempelajari tiga faktor, yaitu :

1. Ukuran dan pertumbuhan segmen konsumen, perusahaan harus mengumpulkan dan menganalisis data tentang penjualan terakhir, proyeksi laju pertumbuhan penjualan dan margin laba yang diharapkan untuk berbagai segmen, kemudian memilih segmen yang paling sesuai.

2. Struktural segmen yang menarik, suatu segmen mungkin mempunyai ukuran dan pertumbuhan yang sesuai dengan harapan, akan tetapi belum tentu menarik dari sisi profitabilitasnya, jadi perusahaan tetap harus mempelajari faktor-faktor struktural utama yang mempengaruhi daya tarik segmen dalam jangka panjang.

3. Sasaran dan sumber daya, perusahaan harus mempertimbangkan sasaran dan kemampuan dalam menyediakan sumber daya.

\section{Positioning}

Positioning adalah tindakan yang dilakukan oleh pelaku pasar untuk membuat citra produk dan hal-hal yang ingin ditawarkan kepada pasarnya berhasil memperoleh posisi yang jelas dan mengandung arti bagi konsumen [2].

Menurut Umar [3], ada 3 langkah dalam melakukan positioning dalam strategi pemasaran, yaitu :

1. Mengidentifikasi keunggulan kompetitif, jika perusahaan dapat menentukan posisinya sendiri dengan memberikan nilai lebih kepada sasaran terpilih, maka perusahaan akan memperoleh keunggulan kompetitif. Jadi posisi berawal dari memberikan sesuatu yang berbeda atas tawaran perusahaan sehingga akan memberikan nilai yang lebih besar dari tawaran pesaing.

2. Memilih keunggulan kompetitif, setelah menemukan keunggulan kompetitif selanjutnya harus memilih satu keunggulan kompetitif sebagai dasar bagi kebijaksanaan penentuan posisinya.

3. Mewujudkan dan mengkomunikasikan posisi, hal ini penting dilakukan agar konsumen mengetahui citra diri dari produk yang ditawarkan.

\section{Retailing}

Menurut Umar [3], Retailing adalah semua kegiatan yang melibatkan penjualan barang dan jasa langsung kepada konsumen. Pada dasarnya retailer mempunyai dua hal penting yang dapat ditawarkan kepada konsumen yaitu produk dan teknik menampilkan produk.

Store environment adalah suasana lingkungan toko yang hendaknya terasa nyaman dan menyenangkan bagi konsumen sehingga konsumen akan menghabiskan waktu dan berbelanja dalam toko. Sedangkan menurut Lewinson dalam Umar [3], store environment memiliki tiga elemen penting, yaitu store image, store atmospherics dan store theatrics.

1. Store image adalah retail yang menggambarkan apa yang dilihat dan dirasakan oleh konsumen terhadap toko tertentu. Store image merupakan citra konsumen terhadap sebuah toko yang terdiri dari kesan terhadap eksterior dan interiornya. Hal ini dilakukan oleh retailer untuk menarik dan memenuhi kepuasan konsumen.

2. Store atmospherics adalah keseluruhan efek emosional yang mampu memuaskan kedua belah pihak, baik retailer maupun konsumen. Atmosfer toko yang menyenangkan hendaknya dapat menarik ke lima indra manusia yaitu penglihatan, pendengaran, penciuman, peraba dan perasa.

3. Store theatrics merupakan konsep yang menonjolkan fungsi tambahan dari toko, di mana diharapkan retailer mampu menyediakan konsep toko yang tidak hanya menekankan pada fungsi tempat belanja tetapi juga sebagai tempat rekreasi dan hiburan, bahkan sebagai tempat bersosialisasi. Dalam praktek bisa berupa mendekorasi toko atau mengadakan acara khusus seperti acara hiburan, program promosi, demonstrasi produk, program sosial dan yang sejenisnya.

\section{Analisis Kelompok}

Analisis kelompok adalah sebuah metode untuk mengelompokkan pengamatan-pengamatan atau obyek-obyek ke dalam beberapa kelompok [5]. Analisis kelompok merupakan suatu metode dalam analisis variabel ganda yang bertujuan untuk mengelompokkan $\mathrm{N}$ satuan pengamatan ke dalam k kelompok $(\mathrm{k}<\mathrm{N})$ berdasar $\mathrm{p}$ variabel, sehingga unitunit pengamatan dalam satu kelompok mempunyai ciri-ciri yang lebih homogen dibandingkan unit pengamatan dalam kelompok lain [6].

Dasar pengelompokan terhadap $\mathrm{N}$ pengamatan ke dalam $\mathrm{k}$ kelompok adalah jarak yang merupakan ukuran kedekatan antar pengamatan [7]. Bila $\mathrm{U}$ dan $\mathrm{V}$ adalah dua pengamatan, maka $d_{(U V)}$ adalah fungsi jarak jika memenuhi sifat sebagai berikut [8] :

1. Simetri, $\mathrm{d}_{(\mathrm{UV})}=\mathrm{d}_{(\mathrm{VU})}$

2. Positif, $\mathrm{d}_{(\mathrm{UV})}>0$

3. $\mathrm{d}_{(\mathrm{UV})}=0$ jika dan hanya jika $\mathrm{U}=\mathrm{V}$

4. Ketidaksamaan segitiga, $\mathrm{d}_{(\mathrm{UV})} \leq \mathrm{d}_{(\mathrm{UW})}+\mathrm{d}_{(\mathrm{WV})}$

Jarak euclid merupakan jarak yang paling sering digunakan dalam analisis dan merupakan ukuran yang paling sederhana untuk variabel kontinu. Rumus jarak euclid adalah [9]: 


$$
d_{i j}=\sqrt{\sum_{k=1}^{p}\left(x_{i k}-x_{j k}\right)^{2}}
$$

di mana:

$d_{i j}=$ jarak antara pengamatan ke-i dan pengamatan ke-j

$x_{i k}=$ pengamatan ke-i pada variabel ke-k

$x_{j k}=$ pengamatan ke-j pada variabel ke-k [10]:

Syarat jarak euclid adalah bahwa variabel yang diamati

a. Tidak saling berkorelasi

b. Mempunyai satuan ukuran yang sama

c. Pengukuran pembakuan mempunyai rata-rata nol dan standar deviasi satu

Jika pengaruh korelasi antar variabel dipertimbangkan, alternatif jarak yang digunakan adalah jarak mahalanobis. Sharma [11] menyatakan bahwa jarak mahalanobis didefinisikan sebagai jarak antara dua titik yang melibatkan peragam atau korelasi antar variabel. Jarak Mahalanobis antara pengamatan ke-i dan ke-j dirumuskan sebagai berikut :

$d_{i j}^{2}=\frac{1}{1-r^{2}}\left[\frac{\left(x_{i 1}-x_{j 1}\right)^{2}}{s_{1}^{2}}+\frac{\left(x_{i 2}-x_{j 2}\right)^{2}}{s_{2}^{2}}-\frac{2 r\left(x_{i 1}-x_{j 1}\right)\left(x_{i 2}-x_{j 2}\right)}{s_{1} S_{2}}\right]$

di mana :

$$
\begin{aligned}
d_{i j} & =\text { jarak antara pengamatan ke-i dan ke-j } \\
x_{i 1} & =\text { pengamatan ke-i pada variabel ke-1 } \\
x_{j 1} & =\text { pengamatan ke-j pada variabel ke-1 } \\
x_{i 2} & =\text { pengamatan ke-i pada variabel ke-2 } \\
x_{j 2} & =\text { pengamatan ke-j pada variabel ke-2 } \\
r & =\text { koefisien korelasi antar dua variabel } \\
S_{1}^{2} \text { dan } S_{2}^{2} & =\text { ragam untuk variabel ke-1 dan ke-2 }
\end{aligned}
$$

Menurut Afifi [5], jarak mahalanobis merupakan generalisasi dari jarak kuadrat euclid yang dibakukan. Pada saat variabel-variabel tidak saling berkorelasi atau $r=0$, maka jarak mahalanobis sama dengan jarak kuadrat euclid yang dibakukan.

Sedangkan untuk kasus yang variabelnya lebih dari dua (p-variabel), maka jarak mahalanobis antara dua pengamatan dinyatakan dalam bentuk vektor dan matrik [11]:

$$
d_{i j}^{2}=\left(\mathbf{x}_{i k}-\mathbf{x}_{j k}\right)^{T} \mathbf{S}^{-1}\left(\mathbf{x}_{i k}-\mathbf{x}_{j k}\right)
$$

di mana :

$d_{i j}=$ jarak antara pengamatan ke-i dan ke-j

$\mathbf{x}_{i k}=$ vektor pengamatan ke-i pada variabel ke- $\mathrm{k}$

$\mathbf{x}_{j k}=$ vektor pengamatan ke-j pada variabel ke-k

$\mathbf{S}=$ matrik ragam peragam

$$
\mathbf{S}=\left[\begin{array}{cccc}
S_{1}^{2} & \operatorname{cov}\left(x_{1}, x_{2}\right) & \ldots & \operatorname{cov}\left(x_{1}, x_{p}\right) \\
\operatorname{cov}\left(x_{2}, x_{1}\right) & S_{2}^{2} & \ldots & \operatorname{cov}\left(x_{2}, x_{p}\right) \\
\ldots & \ldots & \ldots & \ldots \\
\operatorname{cov}\left(x_{p}, x_{1}\right) & \operatorname{cov}\left(x_{p}, x_{2}\right) & \ldots & S_{p}^{2}
\end{array}\right]
$$

$$
\mathbf{S}=\left[\begin{array}{cccc}
S_{1}^{2} & S_{12} & \ldots & S_{1 p} \\
S_{21} & S_{2}^{2} & \ldots & S_{2 p} \\
\ldots & \ldots & \ldots & \ldots \\
S_{p 1} & S_{p 2} & \ldots & S_{p}^{2}
\end{array}\right]
$$

Jarak yang diperoleh diringkas dalam matrik simetri $\mathrm{n} \times \mathrm{n}$ :

$$
\mathbf{D}=\left[\begin{array}{cccc}
0 & d_{12}^{2} & \ldots & d_{1 n}^{2} \\
d_{21}^{2} & 0 & \ldots & d_{2 n}^{2} \\
\ldots & \ldots & \ddots & \ldots \\
d_{n 1}^{2} & d_{n 2}^{2} & \ldots & 0
\end{array}\right]
$$

di mana $\mathrm{d}_{\mathrm{ik}}{ }^{2}=\mathrm{d}_{\mathrm{ki}}{ }^{2}$ dan $\mathrm{d}_{\mathrm{ii}}{ }^{2}=0$.

\section{Metode Pengelompokan Hirarki}

Metode pengelompokan hirarki digunakan untuk mengelompokkan pengamatan secara terstruktur berdasarkan kemiripan sifatnya. Di samping itu, analisis ini digunakan apabila pada awal analisis kurang adanya informasi tentang karakteristik pengamatan-pengamatan yang akan dikelompokkan, sehingga banyaknya kelompok yang diinginkan belum diketahui. Ada dua cara untuk mendapatkan kelompok dengan metode pengelompokan hirarki yaitu dengan cara penggabungan dan pemisahan kelompok [6].

Metode penggabungan dilakukan dengan menganalisis sebanyak $\mathrm{N}$ kelompok (seluruh pengamatan), langkah selanjutnya adalah menggabungkan dua kelompok terdekat sehingga pada akhirnya hanya terbentuk satu kelompok. Sementara metode pemisahan dimulai dengan satu buah kelompok besar kemudian anggota kelompok yang paling tidak mirip atau dekat dengan pengamatan yang lain dipisahkan menjadi kelompok yang lain [5].

Berdasarkan rumus jarak yang digunakan, metode penggabungan ini dibagi menjadi tiga macam [12], yaitu:

1. Metode Pautan Tunggal (Single Linkage)

Metode pautan tungal didefinisikan sebagai jarak minimum antara kelompok (UV) dengan satu atau beberapa pengamatan di luar kelompok yang terbentuk sebelumnya. Jarak antara kelompok (UV) dengan pengamatan $\mathrm{W}$ yaitu:

$\mathrm{d}_{(\mathrm{UV}) \mathrm{W}}=\operatorname{minimum}\left(\mathrm{d}_{\mathrm{UW}}, \mathrm{d}_{\mathrm{VW}}\right)$

2. Metode Pautan Lengkap (Complete Linkage)

Metode pautan lengkap didefinisikan sebagai jarak maksimum antara kelompok (UV) dengan satu atau beberapa pengamatan di luar kelompok yang terbentuk sebelumnya. Jarak antara kelompok (UV) dengan pengamatan $\mathrm{W}$ yaitu:

$\mathrm{d}_{(\mathrm{UV}) \mathrm{W}}=\operatorname{maksimum}\left(\mathrm{d}_{\mathrm{UW}}, \mathrm{d}_{\mathrm{VW}}\right)$

3. Metode Pautan Rata-rata (Average Linkage)

Pada metode ini dihitung jarak minimum antara semua pasangan pengamatan dari kelompok yang digabung. Rata-rata jarak antara kelompok (UV) yang merupakan gabungan jarak antara kelompok $\mathrm{U}$ dan kelompok $\mathrm{V}$ dengan kelompok $\mathrm{W}$ adalah :

$$
d_{(U V) W}=\frac{\sum_{i} \sum_{k} d_{i k}}{n(U V) n(W)}
$$

di mana: 
$\mathrm{d}_{\mathrm{ik}}=$ jarak antara pengamatan ke-i dalam kelompok (UV) dan pengamatan ke-k kelompok W

$\mathrm{n}(\mathrm{UV})=$ banyaknya pengamatan dalam kelompok (UV)

$\mathrm{n}(\mathrm{W})=$ banyaknya pengamatan dalam kelompok W

Langkah-langkah pada pengelompokan hirarki penggabungan untuk mengelompokkan $\mathrm{N}$ pengamatan adalah [12]:

1. Dimulai dengan N kelompok di mana tiap kelompok terdiri dari satu pengamatan matrik jarak atau kemiripan berukuran $\mathrm{N} x \mathrm{~N}$, dinotasikan $\mathbf{D}=\left(\mathrm{d}_{\mathrm{ij}}\right)$.

2. Menentukan matrik jarak untuk pasangan dua pengamatan terdekat, misalnya jarak terdekat antara kelompok $\mathrm{U}$ dan V adalah $\mathrm{d}_{\mathrm{UV}}$.

3. Menggabungkan kelompok $\mathrm{U}$ dan $\mathrm{V}$ menjadi satu kelompok baru yaitu kelompok (UV). Elemen matrik jarak dapat diperbarui dengan cara :

a. Menghapus baris dan kolom yang menghubungkan kelompok U dan $\mathrm{V}$.

b. Menambah baris dan kolom yang berisi nilai jarak antara kelompok (UV) dengan kelompok-kelompok yang tersisa.

4. Mengulangi langkah 2 dan 3 sebanyak $N$ kali sampai semua pengamatan masuk dalam satu kelompok.

Pada setiap langkah, kelompok yang terjadi digambarkan dalam bentuk dendogram. Untuk memperoleh kelompok yang terbentuk, diadakan pemotongan dendogram yaitu pada selisih terbesar antara jarak penggabungan [13].

\section{Analisis Biplot}

Menurut Friendly [14] data yang digunakan berupa matriks data $\mathbf{X}$ dengan $n$ pengamatan dan $p$ variabel yang dikoreksi terhadap nilai rataannya, berpangkat $r$, sebagai berikut :

$$
\mathbf{X}=\mathbf{U L A},
$$

Dengan matriks $\mathbf{U}$ dan A masing-masing berukuran $n \times \mathrm{x} r$ dan $p$ x $r$ sehingga $\mathbf{U} \mathbf{U}^{\prime}=\mathbf{I}_{\mathrm{r}}$ dan $\mathbf{A}^{\prime} \mathbf{A}=\mathbf{I}_{\mathrm{r}}$. Sedangkan $\mathbf{L}$ adalah matriks diagonal dengan unsur diagonalnya $\sqrt{ } \lambda_{1}>\sqrt{ } \lambda_{2}$ $>\ldots .>\sqrt{ } \lambda_{\mathrm{r}}$, dengan $\lambda_{\mathrm{i}}$ adalah akar ciri terbesar ke-i dari matriks $\mathbf{X}^{\prime} \mathbf{X}$ atau $\mathbf{X X}$ ' dan $r$ adalah pangkat matriks $\mathbf{X}$. Unsur-unsur diagonal ini disebut nilai singular matriks $\mathbf{X}$.

Lajur-lajur matriks A disebut vektor singular baris yang merupakan landasan ortonormal baris-baris matriks $\mathbf{X}$ dalam ruang berdimensi $p$. Lajur-lajur matriks $\mathbf{U}$ disebut vektor singular lajur yang merupakan landasan ortonormal lajurlajur matriks $\mathbf{X}$ dalam ruang berdimensi $n$.

Menurut Jollife dalam Friendly [14]), misalkan $\mathbf{G}=\mathbf{U L}^{\alpha}$ dan $\mathbf{H}=\mathbf{L}^{1-\alpha} \mathbf{A}^{\prime}$, dengan $\alpha$ adalah nilai faktorisasi yang besarnya $0 \leq \alpha \leq 1$, maka persamaan (8) menjadi

$$
\mathbf{X}=\mathbf{G H}^{\prime}
$$

(10)

Atau

$$
\mathbf{x}_{\mathrm{ij}}=\mathbf{g}_{\mathrm{i}} \mathbf{h}_{\mathrm{j}}{ }^{\prime}
$$

dengan $g_{i}$ dan $h_{j}$ masing-masing merupakan baris-baris matriks $\mathbf{G}$ dan $\mathbf{H}$. Jika $\mathbf{X}$ berpangkat dua, maka vektor baris $\mathbf{g}_{\mathrm{i}}$ dan vektor lajur $\mathbf{h}_{\mathrm{j}}$ dapat digambarkan dalam ruang berdimensi dua. Jika $\mathbf{X}$ berpangkat lebih dari dua, biasanya didekati dengan matriks berpangkat dua dan persamaan (10) menjadi

$$
{ }_{2} \mathbf{X}_{\mathrm{ij}}=\mathbf{g}_{\mathrm{i}}{ }^{*} \mathbf{h}_{\mathrm{j}}{ }^{*}
$$

dengan ${ }_{2} \mathbf{X}_{\mathrm{ij}}$ merupakan unsur pendekatan matriks $\mathbf{X}$ pada dimensi dua, sedangkan $\mathbf{g}_{\mathrm{i}}{ }^{*}$ dan $\mathbf{h}_{\mathrm{j}}{ }^{*}$ masing-masing unsurnya terdiri dari komponen utama pertama dan komponen utama kedua matriks $\mathbf{G}$ dan matrik $\mathbf{H}$.

Meskipun faktorisasi $\mathbf{X}=\mathbf{G H}$ tidak khas, tetapi pengambilan nilai $\alpha=0$ berguna bagi interpretasi biplot. Pengambilan nilai ini menghasilkan $\mathbf{G}=\mathbf{U}$ dan $\mathbf{H}=\mathbf{L A}$ ' sehingga diperoleh :

$$
\begin{gathered}
\mathbf{X}^{\prime} \mathbf{X}=\left(\mathbf{G H}^{\prime}\right)^{\prime}\left(\mathbf{G H}^{\prime}\right) \\
=\mathbf{H G} \mathbf{G H}^{\prime} \\
\mathbf{G}^{\prime} \mathbf{G}=\mathbf{I} \text {, sehingga } \\
\mathbf{X}^{\prime} \mathbf{X}=\mathbf{H H},
\end{gathered}
$$

Karena $\mathbf{X}^{\prime} \mathbf{X}=\mathbf{H H}^{\prime}=(\mathrm{n}-1) \mathbf{S}$, maka hasil kali $\mathbf{h}_{\mathrm{j}}{ }^{\prime} \mathbf{h}_{\mathrm{k}}$ akan sama dengan (n-1) kali peragam $\mathbf{S}_{\mathrm{jk}}$ dan $\mathbf{h}_{\mathrm{k}}{ }^{\prime} \mathbf{h}_{\mathrm{k}}$ menggambarkan keragaman variable ke-k, sedangkan korelasi variabel ke-j dan ke-k sama dengan nilai kosinus sudut antara vektor $\mathbf{h}_{\mathrm{j}}$ dan $\mathbf{h}_{\mathrm{k}}$.

Dengan demikian interpretasi biplot antara lain:

1. Panjang vektor variabel sebanding dengan keragaman variabel tersebut. Semakin panjang vektor suatu variabel maka keragaman variabel tersebut semakin tinggi.

2. Nilai cosinus sudut antara dua vektor variabel menggambarkan korelasi kedua variabel. Semakin sempit sudut yang dibuat antara dua variabel maka semakin positif tinggi korelasinya. Jika sudut yang dibuat tegak lurus maka korelasi keduanya rendah. Sedangkan jika sudutnya tumpul (berlawanan arah) maka korelasinya negatif.

3. Posisi obyek yang searah dengan suatu vektor variabel diinterpretasikan sebagai besarnya nilai variable untuk obyek yang searah dengannya. Semakin dekat letak obyek dengan arah yang ditunjuk oleh suatu variabel maka semakin tinggi variabel tersebut untuk obyek itu. Sedangkan jika arahnya berlawanan, maka nilainya rendah.

4. Kedekatan letak atau posisi dua buah obyek diinterpretasikan sebagai kemiripan sifat dua obyek. Semakin dekat letak dua buah obyek maka sifat yang ditunjukkan oleh nilai-nilai variabelnya semakin mirip

\section{METODOLOGI PENELITIAN}

\section{Sumber Data}

Pada penelitian ini banyaknya populasi besar dan tidak diketahui, untuk itu dilakukan sampling (pengambilan sampel). Sampel di sini adalah konsumen Plaza Araya yang pernah berbelanja di Mitra I. Selanjutnya dilakukan survei untuk mendapatkan data (data primer).

Teknik pengambilan sampel untuk menentukan banyaknya sampel adalah teknik simple random sampling. Teknik ini dipilih karena diasumsikan bahwa seluruh konsumen adalah homogen, yaitu sebagai konsumen Plaza Araya dan pernah berbelanja di Mitra I.

Sebelumnya dilakukan survei pendahuluan dengan mengambil sampel sebanyak 30 konsumen. Karena tidak diketahui adanya penelitian tentang konsumen Plaza Araya sebelumnya, maka peneliti menetapkan tingkat keyakinan 95\% dan sampling error sebesar 10\%. Selain itu untuk menduga proporsi sebenarnya dari populasi, digunakan proporsi konsumen yang memilih Plaza Araya sebagai shopping center yang disukai dan proporsi konsumen yang lebih menyukai berbelanja di shopping center lain. Selanjutnya digunakan rumus sebagai berikut [15]: 


$$
\hat{p}=\frac{X}{n}
$$

di mana :

$$
\begin{aligned}
\hat{p}= & \text { Proporsi konsumen yang memilih Plaza Araya } \\
& \text { sebagai shopping center yang disukai } \\
X= & \text { Banyaknya konsumen yang memilih Plaza } \\
& \text { Araya sebagai shopping center yang disukai } \\
n= & \text { Banyaknya konsumen dalam survei pendahuluan }
\end{aligned}
$$

Dari rumus (13) didapatkan proporsi konsumen yang memilih Plaza Araya sebagai shopping center yang disukai sebesar 0,567 dan proporsi konsumen yang lebih menyukai berbelanja di shopping center lain sebesar 0,433.

Karena populasi konsumen Plaza Araya secara pasti tidak diketahui, maka banyaknya sampel ditentukan berdasarkan rumus [16]:

$$
N=\left[\frac{t_{n-1}^{\alpha / 2}}{d}\right]^{2} \hat{p} \hat{q}
$$

di mana :

$$
\begin{aligned}
\mathrm{N}= & \text { Banyaknya sampel } \\
\hat{p}= & \begin{array}{l}
\text { Proporsi konsumen yang memilih } \\
\end{array} \\
& \text { Plaza Araya sebagai shopping center } \\
& \text { yang disukai } \\
\hat{q}= & \text { proporsi konsumen yang memilih } \\
& \text { shopping center lain } \\
d= & \text { Sampling error } \\
\alpha / 2= & \text { Sebaran t dengan derajat bebas } \mathrm{n}-1
\end{aligned}
$$

Jadi banyaknya sampel yang diambil adalah :

$$
\begin{aligned}
N & =\left[\frac{2,045}{0.1}\right]^{2} 0,567(1-0,567) \\
& =[418,2025] x 0,2455 \\
& =102,6687 \cong 103 \text { konsumen }
\end{aligned}
$$

\section{Definisi dan Identifikasi Variabel}

1. Komponen Demografis : Jenis Kelamin, Usia, Status pernikahan, Pendidikan terkahir, Pekerjaan, Pengeluaran tiap bulan.

2. Komponen Psikografis : Koran yang disukai, radio yang disukai, music yang disukai, jenis transportasi, shopping center yang disukai, frekuensi belanja dalam satu bulan, keinginan belanja, informasi, dan tempat belanja.

3. Faktor-faktor yang mempengaruhi komponen psikografis

a. Price Consciousness : konsumen-konsumen yang lebih menekankan pada harga barang yang akan dibelinya

b. Quality Consciousnes : Konsumen-konsumen tipe ini tidak mempersoalkan harga, mereka lebih mengutamakan kualitas. Bagi mereka kualitas merupakan hal utama dalam membeli barang

c. Image / Prestige : Konsumen pada tipe ini adalah konsumen yang lebih mengutamakan penampilan atau gengsi. Konsumen-konsumen ini tidak hanya memperhatikan kualitas dan harga, namun ada hal yang lebih penting bagi mereka yaitu gengsi

d. Risk Taker : Konsumen-konsumen ini cenderung lebih suka mencoba hal-hal yang baru dalam kehidupannya. Bagi mereka sesuatu yang statis merupakan hal yang sangat membosankan

e. Konservatif : cenderung menyukai segala sesuatu yang sudah dikenal dengan baik di dalam lingkungan kehidupannya

f. Impulsive : cenderung sering terbawa dalam keadaan yang sedang berlangsung di sekitarnya. konsumen ini tak mampu menahan diri dengan segala sesuatu yang baru atau menarik perhatian

g. Well planed : cenderung lebih berhati-hati dan selalu penuh pertimbangan dalam melakukan sesuatu

4. Faktor-faktor dalam Positioning

a. Harga dan kualitas : kesesuaian harga dengan merek dan kualitas, kelengkapan barang, kualitas barang, harga barang, jaminan keamanan/garansi barang rusak

b. Pelayanan : penampilan fisik karyawan, sikap karyawan terhadap konsumen, cara menyampaikan informasi kepada konsumen, kebersihan lantai dan barang, layanan special (undian dan diskon)

c. Fasilitas : lokasi yang strategis, AC, music serta penerangan, jumlah troli dan keranjang, luas ruangan, tatanan dan susunan barang, kecukupan informasi letak barang, sarana pengaduan, parker kendaraan.

\section{Metode Analisis}

Langkah-langkah analisis data untuk mencapai tujuan dalam penelitian ini adalah sebagai berikut :

1. Melakukan transformasi dengan metode rating yang dijumlahkan, proses perhitungan dilakukan dengan makro Minitab.

2. Melakukan uji validitas dan uji reliabilitas terhadap hasil survei pendahuluan. Proses perhitungan dilakukan dengan SPSS for Windows.

3. Kuesioner yang valid dan reliabel ditanyakan kembali kepada 103 konsumen Plaza Araya.

4. Menerapkan analisis kelompok. Proses perhitungan dilakukan dengan bantuan makro Minitab.

5. Menentukan peta posisi terhadap variabel-variabel positioning dengan metode biplot. Perhitungan dilakukan dengan bantuan SAS 6.12.

\section{HASIL DAN PEMBAHASAN}

Berdasarkan komponen demografis konsumen di Plaza Araya dideskripsikan sebagai berikut :

1. $60,19 \%$ atau sebanyak 62 konsumen adalah wanita

2. $45,63 \%$ atau sebanyak 47 konsumen berusia $24-30$ tahun dan sudah menikah

3. $46,60 \%$ telah menyelesaikan pendidikan sampai sarjana.

4. $41,75 \%$ sebagai karyawan swasta.

5. $46,60 \%$ pengeluaran perbulannya di antara $>\mathrm{Rp} 750.000$ - Rp 1.500.000.

Berdasarkan komponen psikografis (gaya hidup dan sosial budaya) konsumen di Plaza Araya dideskripsikan sebagai berikut:

1. 65 atau sebesar $63,11 \%$ menempatkan Koran Jawa Pos sebagai media cetak yang dibaca tiap hari

2. $35,92 \%$ atau sebanyak 37 biasa mendengarkan radio MFM dan musik yang mereka sukai adalah musik pop.

3. $40,78 \%$ menggunakan sepeda motor sebagai alat transportasi dalam berbelanja.

4. $42,72 \%$ mengaku satu kali belanja dalam satu bulannya. 
Dalam analisis kelompok, keanggotaan dari setiap kelompok ditentukan berdasarkan ukuran kedekatan atau jarak. Jarak yang digunakan adalah jarak Mahalanobis. Jarak mahalanobis digunakan apabila korelasi antar variabel diperhitungkan. Nilai korelasi antar variabel dapat dilihat pada lampiran 9. Metode pautan yang digunakan dalam analisis kelompok ini adalah metode pautan rata-rata (average linkage), di mana pada metode ini jarak yang digunakan adalah rata-rata jarak antar individu atau kelompok. Setelah semua individu masuk dalam satu kelompok dan tidak dapat dikelompokkan lagi, yang dapat digambarkan dalam bentuk dendogram, maka dilakukan pemotongan dendogram pada selisih jarak penggabungan terbesar yang dapat dilihat pada Lampiran 10. Pemotongan dilakukan pada jarak 40,95065 Hasil pengelompokan berdasarkan pemotongan dendogram dapat dilihat pada gambar 1 .

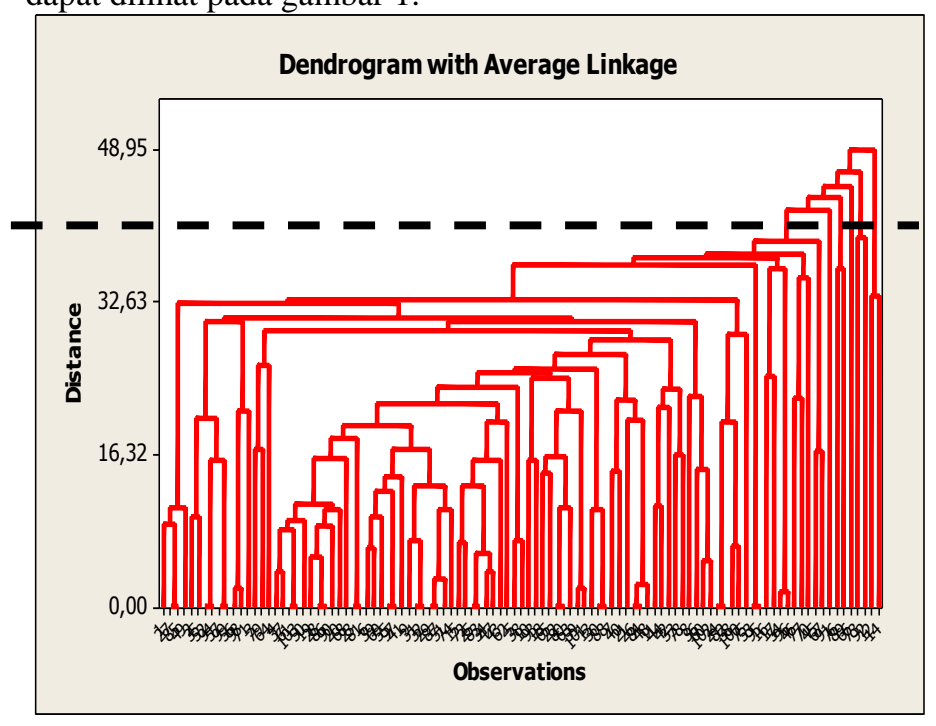

Gambar 1. Dendogram dengan Average Linkage berdasarkan jarak mahalanobis

Dari gambar 1 hasil pemotongan dendogram menghasilkan 6 kelompok. Di mana kelompok-kelompok ini yang akan menentukan segmentasi dari konsumen Plaza Araya berdasarkan komponen Psikografis. Enam kelompok yang terbentuk dapat dilihat pada tabel 1 .

Tabel 1. Hasil pengelompokan data psikografis dan rata-rata variabel tiap kelompok dengan Average Linkage berdasarkan jarak mahalanobis

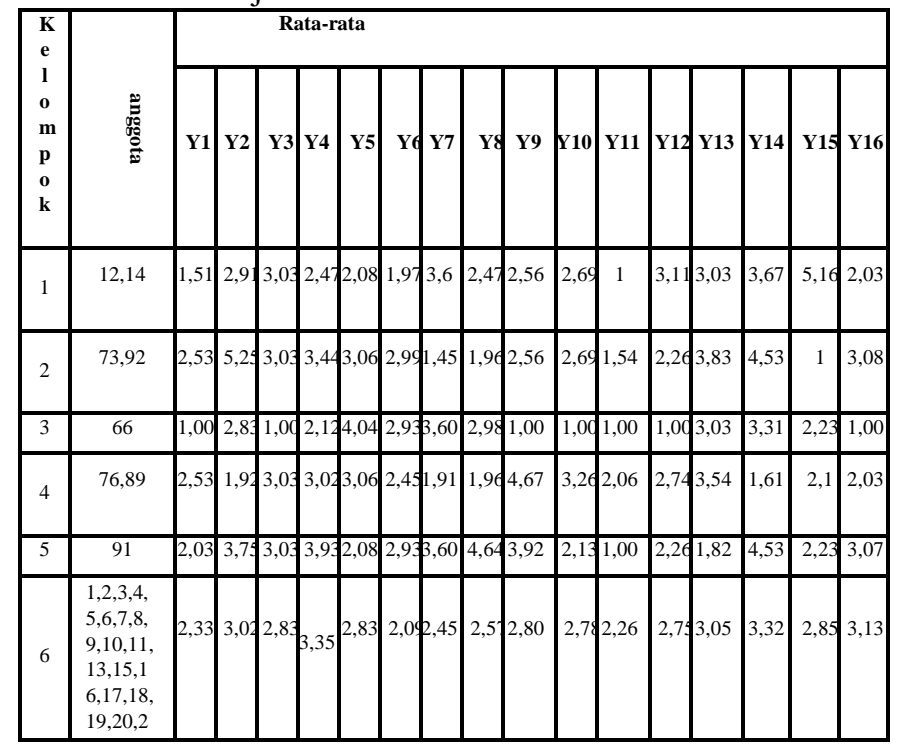

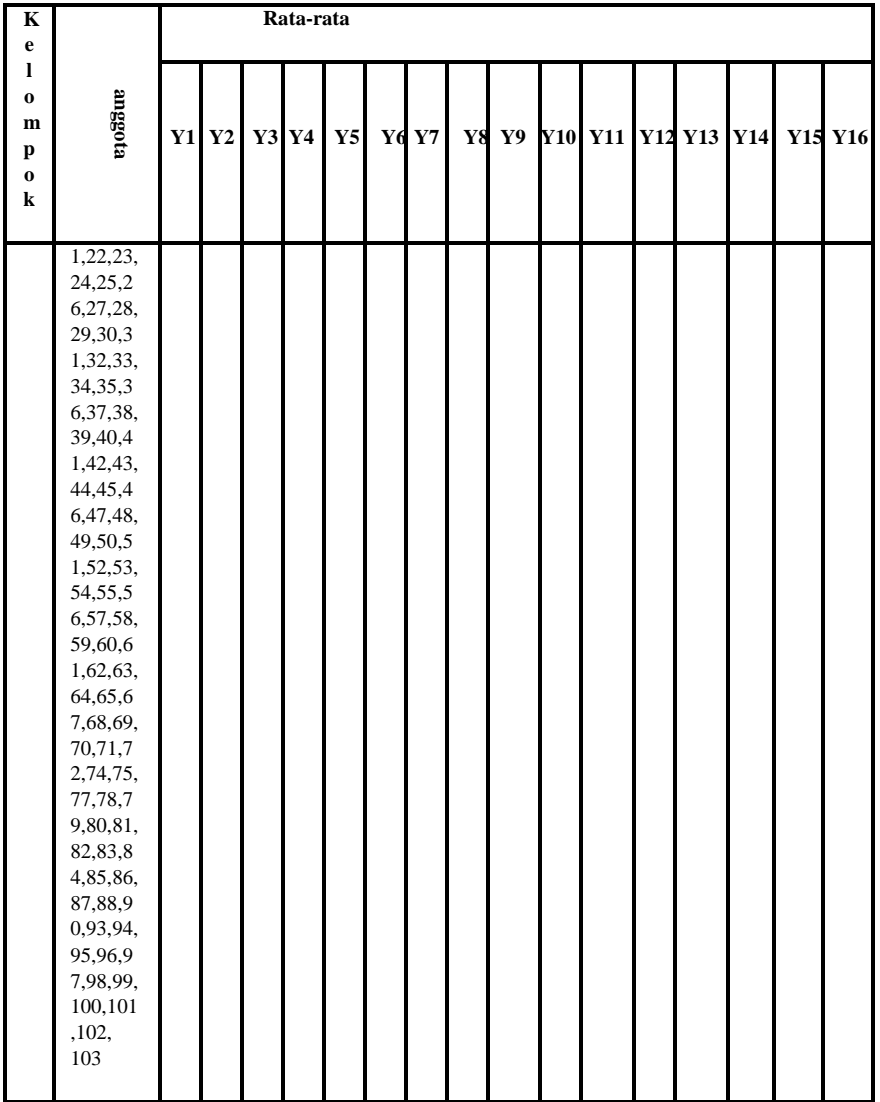

Dari tabel 1 dapat dilihat nilai rata-rata dari masing-masing variabel di setiap kelompok. Dari nilai rata-rata tertinggi dapat diketahui ciri konsumen yang berbelanja di Plaza Araya dan alasan-alasan dalam berbelanja di Plaza Araya.

1. Segmen 1 : Segmen yang pertama ini adalah kelompok dari konsumen Plaza Araya yang menjadikan well planned dengan variabel merencanakan sebelum membeli barang sebagai ciri konsumen yang berbelanja di Plaza Araya. Sehingga dapat disimpulkan bahwa segmen ini dicirikan oleh konsumen yang penuh perencanaan dan pertanggungjawaban.

2. Segmen 2 : Segmen kedua adalah segmen yang dicirikan oleh konsumen yang suka belanja di Plaza Araya dengan memperhatikan harga barang, karena mereka suka membandingkan harga barang yang akan mereka beli. Hal ini dapat dilihat dari nilai rata-rata tertinggi pada faktor price conscicousness pada variabel membandingkan harga barang.

3. Segmen 3 : Dari tabel 1 dapat diketahui nilai rata-rata tertinggi terletak pada faktor quality conscicousness pada variabel harga bukan menjadi suatu permasalahan. Jadi segmen ini dicirikan oleh konsumen yang mempertimbangkan kualitas dan harga bukan menjadi suatu permasalahan.

4. Segmen 4 : Segmen yang keempat ini adalah kelompok dari konsumen Plaza Araya yang menjadikan risk taker dengan variabel suka mencoba-coba barang baru sebagai karakteristik atau ciri konsumen yang berbelanja di Plaza Araya. Hal ini dapat dilihat dari nilai rata-rata tertinggi yaitu sebesar 4,67.

5. Segmen 5 : Di lihat dari tabel 1 nilai rata-rata tertinggi adalah 4,64, jadi segmen ini dicirikan oleh konsumen yang memiliki gengsi tinggi, karena konsumen di segmen ini akan bangga jika orang lain tahu kalau barang yang dibeli harganya mahal. 
6. Segmen 6 : Di lihat dari tabel 1 nilai rata-rata tertinggi adalah 3,35, jadi segmen ini dicirikan oleh konsumen yang lebih mempertimbangkan kualitas, karena kualitas bagi mereka adalah nomer satu.

Dari hasil segmentasi konsumen dapat dilakukan targeting pada segmen 6 yaitu segmen yang dicirikan oleh konsumen yang lebih mempertimbangkan kualitas, karena kualitas bagi mereka adalah nomer satu. Segmen ini perlu dibidik karena dari hasil survei segmen ini memiliki anggota terbanyak yaitu 95 konsumen.

Pada prinsipnya Biplot merupakan upaya grafis terhadap tabel ringkasan dalam dua dimensi, di mana tabel ringkasan tersebut merupakan tabel rata-rata beberapa variabel pada beberapa obyek. Pada penelitian ini tabel memuat rata-rata 2 obyek dan 17 variabel yang dapat dilihat pada tabel 2 .

Tabel 2 Nilai rata-rata dari 2 obyek dan 17 variabel

\begin{tabular}{|c|c|c|c|c|c|c|c|c|c|c|c|c|c|c|c|c|c|}
\hline \multirow{2}{*}{ Obyek } & \multicolumn{9}{|c|}{ Harga dan kualitas } & \multicolumn{6}{|c|}{ Pelayanan } & \multicolumn{7}{|c|}{ Fasilitas } \\
\cline { 2 - 12 } & X1 & X2 & X3 & X4 & X5 & X6 & X7 & X8 & X9 & X10 & X11 & X12 & X13 & X14 & X15 & X16 & X17 \\
\hline $\begin{array}{c}\text { Plaza } \\
\text { Araya }\end{array}$ & 3,05 & 3,18 & 3,57 & 2,71 & 2,97 & 3,33 & 3,34 & 2,96 & 3,18 & 2,89 & 2,66 & 3,05 & 3,17 & 2,89 & 2,89 & 2,82 & 2,81 \\
\hline $\begin{array}{c}\text { Mitra } \\
\text { I }\end{array}$ & 3,34 & 3,18 & 3,60 & 3,18 & 3,33 & 3,06 & 3,18 & 2,97 & 3,18 & 2,97 & 3,05 & 3,33 & 3,58 & 3,34 & 3,59 & 3,58 & 3,59 \\
\hline
\end{tabular}

Dengan menggunakan SAS 6.12 hasil analisis Biplot memberikan gambar seperti terlihat pada gambar 1 .

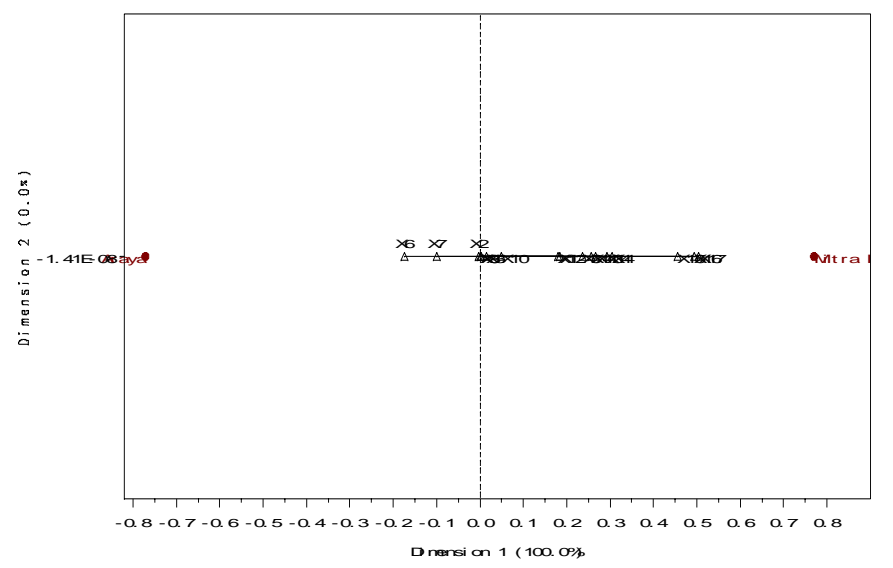

Gambar 2 Biplot untuk menentukan positioning Plaza Araya terhadap Mitra I

Dari gambar 2 dapat dilihat posisi dari Plaza Araya terhadap Mitra I, di mana keduanyan telah memiliki posisi yang berbeda bagi konsumennya. Jarak yang dibentuk antara dua obyek yaitu Plaza Araya dan Mitra I menunjukkan adanya perbedaan yang nyata atau dengan kata lain keduanya telah memiliki keunggulan-keunggulan di bidang tertentu. Plaza Araya lebih unggul dibandingkan Mitra I, unggulan tersebut meliputi penampilan fisik karyawan, sikap karyawan terhadap konsumen dan kelengkapan barang. Sedangkan Mitra I lebih unggul dibandingkan Plaza Araya dalam hal harga, kualitas dan fasilitas.

Perbedaan variabel-variabel psikografis untuk mengetahui segmentasi konsumen dengan variabel-variabel positioning menyebabkan hasil targeting tidak sesuai dengan positioning Plaza Araya. Targeting dilakukan pada segmen konsumen yang lebih mempertimbangkan kualitas, karena kualitas bagi mereka adalah nomer satu. Sedangkan postioning Plaza Araya memiliki keunggulan dalam penampilan fisik karyawan, sikap karyawan terhadap konsumen dan kelengkapan barang.

\section{PENUTUP}

\section{Kesimpulan}

Berdasarkan hasil analisis dan pembahasan didapatkan kesimpulan-kesimpulan sebagai berikut :

1. Dari hasil analisis kelompok untuk komponen psikografis, diperoleh enam kelompok (segmen) konsumen Plaza Araya, di mana segmen tersebut adalah sebagai berikut :

a. Segmen 1 : Dicirikan oleh mereka yang menjadikan well planned dengan variabel merencanakan sebelum membeli barang dalam berbelanja di Plaza Araya.

b. Segmen 2 : Dicirikan oleh mereka yang suka membandingkan harga barang yang akan mereka beli.

c. Segmen 3 : Dicirikan oleh mereka yang mempertimbangkan kualitas dan harga bukan menjadi suatu permasalahan.

d. Segmen 4 : Risk taker dengan variabel suka mencobacoba barang baru sebagai karakteristik atau ciri dalam berbelanja di Plaza Araya.

e. Segmen 5 : Dicirikan oleh mereka yang memiliki gengsi tinggi, karena mereka bangga jika orang lain tahu kalau barang yang dibeli harganya mahal.

f. Segmen 6 : Dicirikan oleh mereka yang lebih mempertimbangkan kualitas, karena kualitas bagi mereka adalah nomer satu.

2. Dari hasil segmentasi konsumen dapat dilakukan targeting pada segmen 6 yaitu segmen yang dicirikan oleh konsumen yang lebih mempertimbangkan kualitas, karena kualitas bagi mereka adalah nomer satu.

3. Berdasarkan analisis Biplot, Plaza Araya lebih unggul dibandingkan dengan Mitra I, unggulan tersebut meliputi penampilan fisik karyawan, sikap karyawan terhadap konsumen dan kelengkapan barang. Sedangkan Mitra I lebih unggul dibandingkan dengan Plaza Araya dalam hal harga, kualitas dan fasilitas.

4. Hasil targeting tidak sesuai dengan positioning Plaza Araya, di mana targeting dilakukan pada segmen konsumen yang lebih mempertimbangkan kualitas, karena kualitas bagi mereka adalah nomer satu. Sedangkan positioning Plaza Araya memiliki keunggulan dalam penampilan fisik karyawan, sikap karyawan terhadap konsumen dan kelengkapan barang.

\section{Saran}

Dari gambaran yang sudah didapatkan, maka saran yang bisa diberikan adalah :

1. Hasil penelitian tersebut dapat digunakan sebagai informasi untuk mendukung perusahaan retail (eceran) di Plaza Araya dalam membuat strategi pemasaran.

2. Hasil ini bagi peneliti lain dapat digunakan sebagai informasi awal untuk penelitian di bidang pemasaran di kota Malang.

3. Hasil targeting hendaknya sesuai dengan positioning sehingga segmentasi benar-benar merupakan satu kesatuan dengan targeting dan positioning.

\section{DAFTAR PUSTAKA}


[1] P. Kotler and G. Amstrong, Principles of Marketing, 7th ed. New Jersey: Prentice-Hall, Inc., 1997.

[2] P. Kotler, Marketing management, 9th ed. New Jersey: Prentice-Hall, Inc., 1997.

[3] H. Umar, Riset Pemasaran dan Perilaku Konsumen. Jakarta: Gramedia, 2000.

[4] R. Kasali, Membidik Pasar Indonesia Segmentasi Targeting Positioning. Jakarta: Gramedia, 1998.

[5] A. A. Afifi, Computer-aided Multivariate Analysis, 2nd ed. New York: Chapman \& Hall, 1990.

[6] A. A. Mattjik, I. M. Sumertajaya, H. Wijayanto, Indahwati, A. Kurnia, and B. Sartono, Aplikasi Analisis Peubah Ganda. Bogor: FMIPA, 2002.

[7] D. S. Duran and P. L. Odell, Cluster Analysis. New York: Mc Graw Hill, 1974.

[8] K. V. Mardia, J. T. Kent, and J. M. Bibhy, Multivariate Analysis. London: Academic Press, Inc., 1979.

[9] M. R. Anderberg, Cluster Analysis for Applications. New York: Academic Press, 1973.

[10] B. F. J. Manly, Multivariate Statistical Methods A Primer. New York: Chapman and Hall, 1986.

[11] S. Sharma, Applied Multivariate Techniques. New York: John Wiley and Sons, Inc., 1996.

[12] R. A. Johnson and D. W. Wichern, Applied Multivariate Statistical Analysis. New York: Prentice Hall International Inc., 1982.

[13] B. S. Everitt and G. Dunn, Cluster Analysis, 2nd ed. London: Heineman Education Books, Ltd., 1980.

[14] M. Friendly, Construct a Biplot of Observations and Variable: SAS Institute Inc., 1989.

[15] S. Yitnosumarto, Dasar-Dasar Statistika, 1st ed. Jakarta: PT Raja Grafindo Persada, 1994.

[16] W. G. Cochran, Teknik Penarikan Sampel. Jakarta: Penerbit Universitas Indonesia, 1991. 